\title{
What was the Jarnadup Bristlebird?
}

\author{
Allan H. Burbidge \\ Department of Environment and Conservation, PO Box 51 , \\ Wanneroo, Western Australia 6946, Australia
}

\begin{abstract}
A 1919 collection of eggs from Jarnadup, near Manjimup, southwestern Australia, was claimed at the time to be from the Western Bristlebird, Dasyornis longirostris. This was subsequently disputed by the expert ornithologists $H$. Whittell and G. Smith. This paper clarifies the discrepancy by comparing dimensions of the eggs for all populations in the genus. Measurements of the eggs, as well as a consideration of the description of the nest, indicate that the clutch is likely to be from the Rufous Bristlebird, Dasyornis broadbenti. This leads to two possible conclusions. The clutch might be the only known collection of eggs of the now extinct western subspecies of the Rufous Bristlebird, D. broadbenti litoralis, and therefore represent a significant extension of the known range of this taxon. The alternative, and favoured, explanation is that there is an error in the location data, and the eggs are from a Victorian collection of D. b. caryochrous.
\end{abstract}

\section{INTRODUCTION}

Historical records of species occurrence are an important source of background information for threatened species management (e.g. Garnett and Crowley, 2000). They can help to clarify changes in the known range of individual species and provide information relevant to an understanding of an organism's ecological requirements, as well as providing specific information, such as clues to focus the search for suitable translocation sites. It is in this context that past records of occurrence of bristlebirds in Western Australia have been investigated. Two bristlebird taxa are known from south-western Australia - the Western Bristlebird (Dasyornis longirostris) and the western subspecies of the Rufous Bristlebird (D. broadbenti litoralis) (Johnstone and Storr, 2004). Both are classified as threatened - D. longirostris is Vulnerable and $D$. broadbenti litoralis is extinct (Burbidge, 2004). As part of this investigation, an historical record from Jarnadup, Western Australia, has been examined more closely, as it is outside the known range of both taxa.

Whittell (1936) noted a collection of two eggs and a nest, said to be of the Western Bristlebird, in the H.L. White Collection, Museum of Victoria (accession number BE03383). It is not clear who identified the eggs - it may have been the collector, or it may have been S.W. Jackson, who was White's collection manager. White's collection register states that the eggs were collected by James Stephens "near Jarnadup, Warren River, South-West Australia" on 10 September, 1919. H.L. White purchased the eggs from James Stephens in 1920. Nothing further is known about James Stephens.
Jarnadup (now known as Jardee) was a railway siding serving a timber mill about five $\mathrm{km}$ SSW of Manjimup (Figure 1). As this is well within the south-west forest block, it is an unusual location for a Western Bristlebird.

There has been, however, some doubt concerning the identification. Whittell (1936), who was a resident of the nearby Bridgetown district, questioned the identity mainly on the basis that $D$. longirostris specimens known to him all came from King George Sound. Smith (1987) argued that the eggs were not of $D$. longirostris because they were rather larger than the measurements given by North (1901) for the single clutch of D. longirostris eggs collected by Masters in the Albany district, and the description of the nest did not match that of $D$. longirostris. However, details of the differences were not given.

There are, therefore, two questions: (1) Is the location correct? and (2) Are the nest and eggs those of Dasyornis and, if so, of which species? This paper documents egg variation in Dasyornis and examines the above questions in the context of historical circumstances and the known distribution of Dasvomis species in Western Australia.

\section{METHODS}

All known historical and contemporary occurrences of bristlebirds in Western Australia have been compiled as part of the recovery efforts for the threatened Western Bristlebird (Cale and Burbidge, 1993; S. Gilfillan, S. Comer, A.H. Burbidge, J. Blyth and A. Danks, unpublished). The source of these records is omithological literature 
and unpublished data gathered by A.H. Burbidge, S. McNee, B. Newbey and others.

In order to determine the identity of the Jarnadup eggs, I examined and measured all Dasyornis eggs in the Museum of Victoria, South Australian Museum and Queensland Museum. Measurements for the Masters clutch of $D$. longirostris from Albany were obtained from North (1901) and for one clutch of $D$. brachypterus from the RAOU Nest Record Scheme (measured by R. Jordan). Two clutches of $D$. broadbenti and one of $D$. longirostris in the Natural History Museum, Tring, were measured by D.G.D. Russell. Measurements of two clutches of $D$. longirostris were obtained from Johnstone and Storr (2004).

Bristlebird eggs in the H.L. White collection were also independently checked visually by N. Kolichis, who has expert knowledge in egg identification.

\section{RESULTS}

\section{Location}

When all known records of occurrence are considered, Jarnadup is well outside the known historical distribution of both $D$. longirostris and $D$. broadbenti (Figure 1). The only known occurrences of $D$. broadbenti in Western Australia were near Cape Mentelle, about $100 \mathrm{~km}$ WNW of Jarnadup, and near Cape Naturaliste, about $45 \mathrm{~km}$ north of
Cape Mentelle. D. longirostris is currently only known from between Hopetoun and Albany, about $200 \mathrm{~km}$ ESE. of Jarnadup, although a small number of birds has recently been translocated to near Walpole, $100 \mathrm{~km}$ to the south-east of Jarnadup (Burbidge, 2003). Historically, the Western Bristlebird was also known from some $150 \mathrm{~km}$ to the ESE at Wilson's Inlet in the early 1900s (Whittell, 1936), from another Gilbert record from near Perth (about $250 \mathrm{~km}$ to the north) in 1839 (Whittell, 1941; Fisher, 1992) and a sub-fossil deposit $90 \mathrm{~km}$ west of Jarnadup at Skull Cave (Baird, 1991).

\section{Eggs}

Are the eggs bristlebird eggs?

The Jarnadup eggs are heavily marked all over with fine chocolate brown markings (Figure 2) and measure $28.7 \times 21.1 \mathrm{~mm}$ and $27.8 \times 21.2 \mathrm{~mm}$. This is within the range of sizes for bristlebird species, but larger than the eggs of other Australian passerines (Rufous Treecreeper and songlarks) with eggs of similar size, colour and patterning (Table 1), indicating that there has not been confusion with another genus. The clutch size of two is also consistent with bristlebirds - in the present data set, clutch size was invariably two in the Rufous Bristlebird $D$. broadbenti $(\mathrm{n}=52)$, Eastern Bristlebird D. brachypterus $(\mathrm{n}=7)$, and Western Bristlebird $D$. longirostris $(\mathrm{n}=2)$. Egg colour and

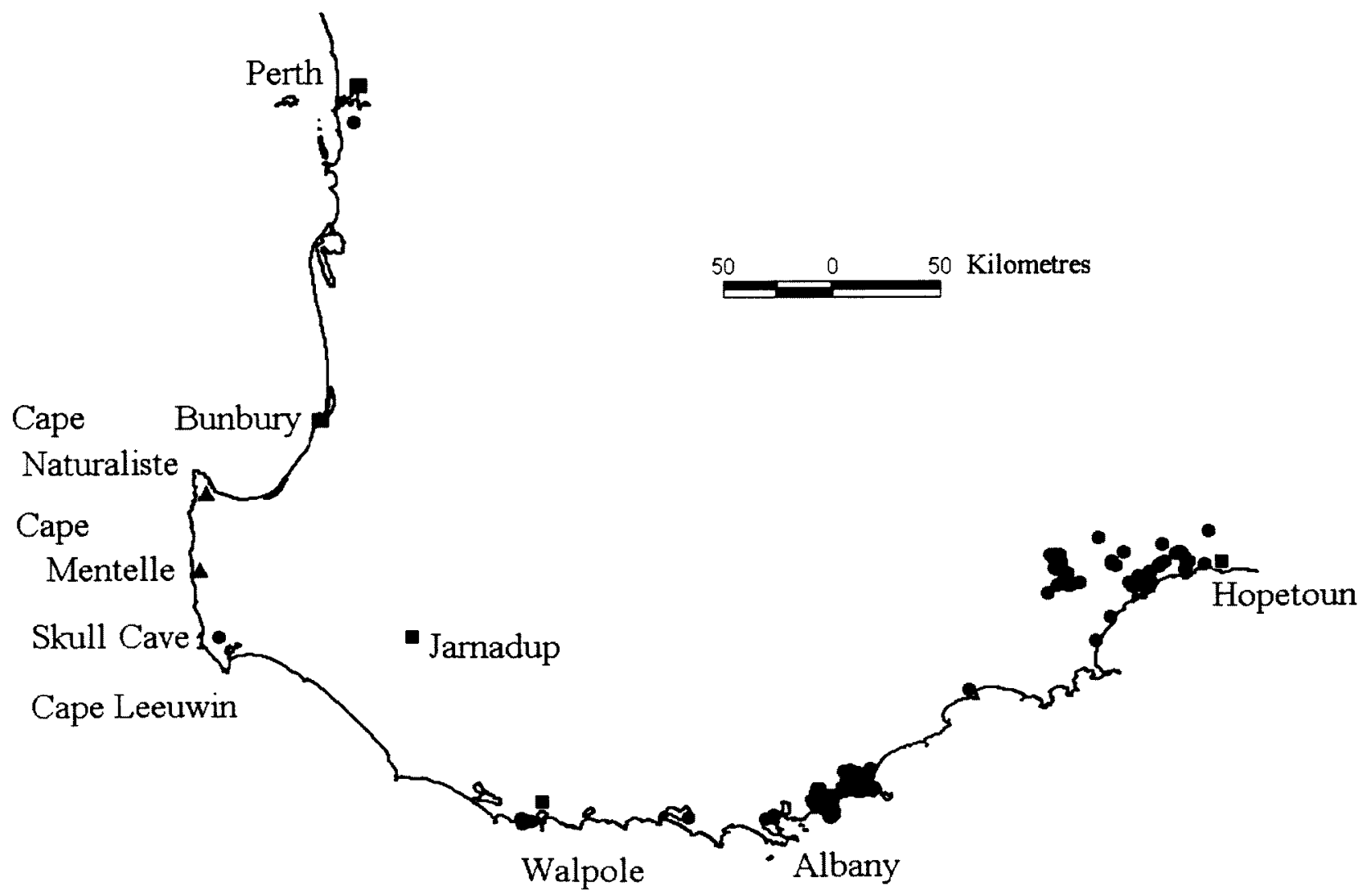

Figure 1 Map of south-western Australia showing the historical distribution of the Western Bristlebird (solid circles), Rufous Bristlebird (solid triangle) and place names mentioned in the text (solid squares for townships). 


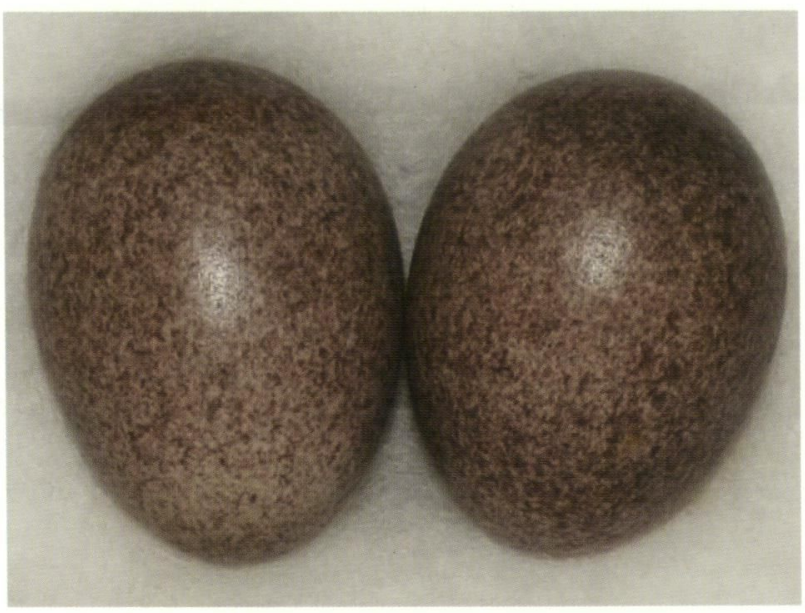

Figure 2 Clutch of bristlebird eggs (accession number BE03383) from the H.L. White Collection, Museum of Victoria, said to have been collected near Jarnadup, Western Australia. Photograph by Jamie MacFadyen, courtesy R. O'Brien and the Museum of Victoria.

pattern varies considerably in bristlebirds, sometimes even within a clutch. These characters are therefore not very useful for distinguishing between bristlebird species. However, on the basis of colour, pattern and shape, the Jarnadup eggs do appear to be from one of the bristlebirds.

\section{Which bristlebird species laid the eggs?}

Given that the eggs are genuine Dasyornis eggs, known bristlebird eggs were therefore examined in more detail. However, apart from the Jarnadup collection, there are few known collections of bristlebird eggs from Western Australia. The rarity of collections of eggs of $D$. longirostris means that such collections would have been highly prized by oologists, some of whom were competitive collectors prepared to pay significant sums for eggs of rare species (Robin, 2001). It is therefore worth documenting known genuine clutches that were in existence at the time that H.L. White was amassing his collection.

John Gilbert apparently collected two sets of $D$. longirostris eggs. First, Gilbert (in Fisher, 1992) recorded having collected "one nest of this bird .... in a thickly scrubbed Plain near the Beach about four Miles to the South of Fremantle November 28 $1839^{\prime \prime}$. Second, a nest with two eggs was collected by John Gilbert in the Albany district during his second visit to Western Australia (1842-43) (Whittell, 1941). A clutch of two eggs in the Gould collection at the Natural History Museum, Tring, and labelled "Western Australia" appears to be a Gilbert collection (C.T. Fisher, pers. comm.). The collection is not dated, and it is unclear whether it is from near Fremantle or Albany. However, given that all Gilbert's extant skins of $D$. longirostris appear to be from King George's Sound, it is likely that the eggs in the Natural History Museum are also from near Albany. The fate of the other Gilbert collection is unknown.

Another nest with two eggs was collected by G. Masters in the Albany district in the late 1860s (Smith, 1987) and these are now in the Australian Museum, Sydney. Johnstone and Storr (2004) note two other collections from near Albany.

In addition, an old infertile egg of $D$. longirostris, collected by F.L. Whitlock at Wilson's Inlet, was broken during attempts to blow it (Whitlock, in Whittell 1936). The fragments were added to the H.L. White Collection, but removed from the collection in 1926 (notes in H.L. White Collection Register). There are no other known collections that are certainly of $D$. longirostris eggs.

One other possible collection is represented by a fragment (the small end of the egg) in the Len Harvey collection, Museum of Victoria. According to Harvey's hand written notes, this egg was said to have been collected in the Bunbury area in 1898, and given to Harvey when he visited Bunbury in 1966. It was considered by Harvey to be an egg of $D$. longirostris, but reasons for this are unknown. No other information is available. The fragment is heavily marked, and is similar in colouration and markings to $D$. broadbenti eggs from Victoria, and rather more heavily marked than Gilbert's $D$. longirostris collection. It is therefore possible that this egg was from $D$. broadbenti litoralis.

The Jarnadup eggs are also similar in colouration

Table 1 Measurements of eggs of bristlebirds (this study), and of species (Climacteris, Cincloramphus) with similar eggs (Johnstone and Storr 2004).

\begin{tabular}{|c|c|c|c|c|c|c|c|}
\hline Species & $\begin{array}{l}\text { Dasyornis } \\
\text { rachypterus }\end{array}$ & $\begin{array}{r}D . \\
\text { broadbenti }\end{array}$ & $\begin{array}{r}D . \\
\text { longirostris }\end{array}$ & $\begin{array}{l}\text { Jarnadup } \\
\text { clutch }\end{array}$ & $\begin{array}{r}\text { Climacteris } \\
\text { rufa }\end{array}$ & $\begin{array}{r}\text { Cincloramphus } \\
\text { mathewsi }\end{array}$ & $\begin{array}{r}\text { C. } \\
\text { cruralis }\end{array}$ \\
\hline No of clutches & 7 & 52 & 4 & 1 & 10 & 16 & 17 \\
\hline No of eggs measured & 13 & 99 & 8 & 2 & 22 & 42 & 48 \\
\hline Mean Length (mm) & 26.6 & 29.9 & 23.5 & 28.3 & 23.7 & 21.2 & 23.4 \\
\hline SD & 1.38 & 1.33 & 0.77 & 0.64 & & & \\
\hline Range & $25.2-28.8$ & $27.2-33.7$ & $22.4-24.8$ & $27.8-28.7$ & $21.2-26.5$ & $19.2-23.0$ & $21.6-25.8$ \\
\hline Mean Width (mm) & 19.9 & 21.5 & 18.4 & 21.2 & 17.9 & 15.5 & 16.9 \\
\hline SD & 1.38 & 0.58 & 0.33 & 0.07 & & & \\
\hline Range & $17.8-22.9$ & $19.9-23.0$ & $17.8-18.7$ & $21.1-21.2$ & $16.7-20.0$ & $14.5-17.0$ & $15.8-18.5$ \\
\hline
\end{tabular}


to $D$. broadbenti eggs. They are finely and densely blotched, of a size and appearance typical of bristlebird eggs. However, there appear to be no collections of eggs of $D$. b. litoralis (from southwestern Australia) for comparison.

Measurements of the Jarnadup eggs fall within the range of measurements of 99 eggs from 52 clutches of $D$. broadbenti (Table 1). They are also within the range of egg size for D. brachypterus, but this species is only known from the eastern seaboard, and the background colour of $D$. brachypterus eggs is usually paler. As noted by Smith (1987), the Jarnadup eggs are distinctly larger than the two $D$. longirostris eggs from the Masters collection measured by North (1901). The eggs of the Gilbert collection are very similar in size to those of the Masters collection. However, the small number of $D$. longirostris eggs available means that we do not know the extent of variation in egg size in that species. It is possible, though unlikely given the smaller size of the bird (Schodde and Mason, 1999; Higgins and Peter, 2002), that some eggs of $D$. longirostris could be as large as the Jarnadup eggs. In addition, the possibility of geographic variation in $D$. broadbenti egg size has some bearing on the amount of confidence we can have assigning the Jarnadup eggs to a particular taxon.

Keast (1957), on a very small sample, showed that wing and bill lengths in $D$. broadbenti are smallest in Western Australia, intermediate in South Australian birds, and longest in Victorian birds. It is possible, therefore, that egg size might vary in a similar fashion.

Schodde and Mason (1999) divide D. broadbenti into three subspecies: litoralis between Cape Naturaliste and Cape Mentelle in south-western Australia, broadbenti from the Murray mouth, South Australia to Port Fairy in Victoria, and caryochrous in and near the Otway Ranges. This differs from the traditional treatment (Condon, 1951; Keast, 1957) in which the eastern populations are separated at the South Australian - Victorian border: D. b. whitei in South Australia and $D$. b. broadbenti in Victoria. (Note that as the type locality is in western Victoria, determination of the affinities of this population determines which subspecific names are available see Schodde and Mason (1999) for details).

There is a very slight difference in egg length between the two subspecific taxa of $D$. broadbenti in south eastern Australia, but these differences are not statistically significant (Table 2 ). The result is the same if the earlier taxonomy of Condon (1951) is used. In both cases eggs from birds in eastern Victoria are shorter than those from birds in South Australia. However, the trend in egg size is consistent with the trend in body size noted by Keast (1957) and would lead to a prediction that eggs of $D . b$. litoralis would be slightly smaller than those from populations in eastern Australia. The
Table 2 Comparison between the Jarnadup egg measurements and those of subspecies of $D$. broadbenti recognised by Schodde and Mason (1999). No eggs of D. b. litoralis are available for comparison.

\begin{tabular}{lrrrrr}
\hline Subspecies & n $\begin{array}{r}\text { Egg length } \\
\text { (mean, } \\
\text { mm) }\end{array}$ & SD & $\begin{array}{r}\text { Egg width } \\
\text { (mean, } \\
\text { mm) }\end{array}$ & SD \\
\hline caryochrous & 53 & 30.1 & 1.46 & 21.5 & 0.55 \\
broadbenti & 46 & 29.7 & 1.14 & 21.5 & 0.63 \\
Jarnadup eggs & 2 & 28.3 & 0.64 & 21.2 & 0.07 \\
\hline
\end{tabular}

Jarnadup eggs are smaller than about $80 \%$ of eggs of eastern $D$. broadbenti, consistent with this hypothesis.

Mean egg length in bristlebird taxa is proportional to mean wing length, which is a surrogate for body size. Using the data for taxa other than $D$. b. litoralis gives a regression equation of $\mathrm{Y}=7.4+0.247 \mathrm{X}$, where $\mathrm{Y}$ is mean egg length and $X$ is mean wing length. On this basis, mean egg length for $D$. b. litoralis is estimated to be $29.0 \mathrm{~mm}$. The mean length of the two Jarnadup eggs is 28.3 $\mathrm{mm}$, close to the estimated value for $D$. b. litoralis, suggesting that it is possible that the Jarnadup eggs are from this taxon.

However, a final consideration relates to the overall appearance of the Jarnadup eggs. In colour, pattern and shape they are very similar to collections from Victorian D. broadbenti. Examination of all the bristlebird eggs in the H.L. White collection by the author and by N. Kolichis (pers. comm.) revealed that the Jarnadup eggs are almost identical in colour, shape and pattern to a 1921 collection by H.A. Purcell from Roadknight Point, near Anglesea, Victoria, labelled $614 \mathrm{H}$ in the H.L. White collection. Interestingly, the eggs in this clutch are also small for $D$. b. caryochrous, measuring $27.7 \times 21.3 \mathrm{~mm}$ and $28.1 \times 21.6 \mathrm{~mm}$, almost identical to the measurements of the Jarnadup eggs. In addition, the Jarnadup eggs were blown using only a single hole in each egg, indicating that this was done by an experienced and competent collector. The set marks and holes match closely those of the Purcell collection from Anglesea (N. Kolichis, pers. comm.). James Stephens is not known as a collector; in fact, examination of records held at the Western Australian Museum show no collections made by him (R.E. Johnstone, pers. comm.) and Museum Victoria records show that only one other collection is known (R. O'Brien, pers. comm.). Such an inexperienced collector would be likely to use two holes, one at each end, to blow an egg.

\section{Nests}

The collector's notes for the Jarnadup collection, 
as stated in the H.L. White collection register are as follows: "Nest 2 feet from the ground in clump of bushes and vines, nest dome-shaped and composed of sticks, bark and grass, lined with fine grass".

All bristlebirds have dome-shaped nests, but they differ in placement of the nest (Higgins and Peter, 2002). Apart from the Jarnadup nest, all known bristlebird nests in Western Australia have been within $45 \mathrm{~cm}$ of the ground (Whittell, 1936; Smith, 1987). In contrast, Rufous Bristlebird nests (in eastern Australia) are on average $90 \mathrm{~cm}$ above ground, and can be as high as $17.0 \mathrm{~cm}$ (Higgins and Peter, 2002). The height of the Jarnadup nest (60 $\mathrm{cm}$ ) is therefore consistent with sites used by Rufous, but not Western, Bristlebirds.

Western Bristlebird nests are constructed mostly of rushes, sedges or sedge-like materials, apparently with little or no lining (for photographs of a Western Bristlebird nest see Taylor (1985)). Rufous Bristlebird nests are made of a broader range of materials, including rushes, sedges, sticks, twigs, bark and leaves. They are normally lined with material such as strips of bark, fine dry grass or fur (Smith, 1987; Higgins and Peter, 2002). The presence of a lining of fine grasses in the Jarnadup nest is therefore consistent with what is known concerning Rufous Bristlebird nests, but is unlikely to indicate a Western Bristlebird.

Rufous Bristlebird nests are rather larger than Western Bristlebird nests, but measurements of the Jarnadup nest are not available and recent searches in the Museum of Victoria failed to locate it.

\section{DISCUSSION}

Egg measurements and colouration, nest site, nest materials and nest lining of the Jarnadup collection are consistent with those of Rufous rather than Western Bristlebird. The mean length of the Jarnadup eggs is closest to that predicted for the now extinct $D$. b. litoralis, for which there are no known clutches. However, the size and colouration of the eggs match closely those of some eggs of $D$. $b$. caryochrous and the method of collection is inconsistent with that of an inexperienced collector. Taken together, these facts suggest that the Jarnadup eggs may have been collected by an experienced collector in the Roadknight Point area of Victoria, and it is even possible that they were laid by the same female as laid Purcell's $614 \mathrm{H}$ collection. Also, while the clutch was given the number 613 in the H.L. White collection, recent examination of data slips by R. O'Brien has shown that there are two slips with 613 written on them one refers to James Stephens and the Jarnadup location, while the other refers to a collection of an egg of $D$. longirostris collected F. Lawson Whitlock at Wilson's Inlet, Western Australia, in 1914. It seems there are some problems in documentation. of Dasyornis clutches in the collection. It is possible that (i) there was a mistake made during the original documentation of the collection, (ii) a mistake was made during transcription of data, (iii) an unknown party intentionally falsified the collection data in order to attract a greater reward for a rare collection, or (iv) the original collection was actually from Jarnadup in Western Australia but someone exchanged the eggs for the more commonly collected $D$. broadbenti eggs. Given the confusion on the data labels, it is likely that an honest mistake has been made. Nevertheless, given the extreme rarity of collections of clutches of $D$. longirostris, and the intense and competitive interest in egg collecting a century ago (Robin, 2001), it is also possible that dishonesty may have come to play. McEvey (1981) listed a relatively small number of errors known in the H.L. White collection but, quoting N.J. Favaloro, also noted that "the authenticity of a clutch depends so much upon the integrity and expertise of the original collector, that mistakes both honest and otherwise must occur from time to time". It seems likely that the Jarnadup clutch is an example of such a mistake, honest or otherwise.

There is no independent evidence concerning the accuracy of the description of the collecting location. There is only one other collection attributed to James Stephens in the Museum of Victoria, and there is no indication that the location is incorrect for that collection. McEvey (1981) lists seven examples of errors of identity or location from the 4200 clutches in the H.L. White collection, but there is nothing in this list to enlighten the current question.

Jarnadup is outside the known range of the Rufous Bristlebird, thought to have been confined to the area between Capes Mentelle and Naturaliste (Higgins and Peter, 2002; Johnstone and Storr, 2004). If the location is correct, this would represent an extension of range by about $90 \mathrm{~km}$ to the east, and about $35 \mathrm{~km}$ further inland than previously known for $D$. $b$. litoralis. Jarnadup is about $40 \mathrm{~km}$ from the coast, equal to the maximum distance to the coast for $D$. longirostris elsewhere in Western Australia. It is a surprising location for a Western Bristlebird given its distance from other known locations, which are mostly near coastal, and the fact that in the Jarnadup area there would only ever have been small pockets of potentially suitable vegetation surrounded by forest. Another possibility, however, is that Jarnadup was simply an indication of a general area. Jarnadup itself is in an area that once would have been forest not bristlebird habitat. To find suitable habitat, one has to go to nearby streamlines that flow into the Warren River, but how far away the collection might have been made, is unknown. In any case, if the location was correct, this would still represents a significant range extension. 
Much of the Jarnadup area has been cleared for agriculture, but some remaining swampy areas include dense heathy vegetation that could have been inhabited by bristlebirds. Western Bristlebirds usually occur in heaths, sometimes in woodlands with a heathy understorey, but not in forest, while Rufous Bristlebirds occur in coastal shrubland and heathland, but occasionally temperate rainforest in Victoria (Higgins and Peter, 2002). It may therefore be possible that a bristlebird could once have occurred in the Jarnadup area, but no recent searches have been made.

The existence of sub-fossil material of $D$. longirostris from Skull Cave, near Cape Leeuwin, suggests that this species might once have occurred along the south coast to the east of there, and hence may have once been sympatric with $D$. broadbenti. There are no other known cases of sympatry in Dasyornis. However, it is also interesting that S.W. Jackson, a very experienced field worker, did not record either bristlebird species in the Irwin Inlet to Broke Inlet area when he searched there in 1912 (Abbott, 1998). With or without the possible Jarnadup occurrence, the exact nature of the historical distribution of bristlebirds between Cape Leeuwin and Irwin Inlet therefore remains a mystery.

Previous searches for $D . b$. Iitoralis have focused on the Leeuwin-Naturaliste Ridge, near the type locality. While the results of the present investigation indicate that the Jarnadup record is probably in error, it does highlight the possibility that Rufous Bristlebirds may have occurred further east in Western Australia than previously thought. Any future searches for this taxon should include likely habitat from Jarnadup southwards, although it seems likely that much of the potentially suitable habitat in this area has been lost, fragmented or been subject to inappropriate burning regimes. The conclusions of this study also indicate that, given that the Jarnadup bristlebird was not a Western Bristlebird and there is considerable doubt about the validity of the location data, it is not worth searching the Jarnadup area for potential translocation sites for Western Bristlebirds. These conclusions illustrate the value that historical museum collections could have in contributing to modern day recovery efforts for species that, by their very nature, are often difficult to study because of their rarity. In the case of bristlebirds, they are also cryptic. However, the study also highlights the importance of making, and maintaining, accurate, precise and unambiguous records of species identity and collection location.

\section{ACKNOWLEDGEMENTS}

Dr Graeme Smith first alerted me to the unusual aspects of the Jarnadup eggs; I thank him for his encouragement to pursue these issues. Dr Leslie Christidis and Mr Rory O'Brien arranged access to the H.L. White and L. Harvey collections in the Museum of Victoria, and Dr Philippa Horton and Ms Maya Penck, South Australian Museum, facilitated access to the Morton-Oakley and S.A. White Collections, which are in their care. I would also like to thank the Queensland Museum for access to their collections. Dr Clemency Fisher of National Museums Liverpool, UK, located the Gilbert collection, and Douglas Russell of the Bird Group, Natural History Museum, Tring, kindly measured and photographed these eggs. Ian Mason provided insightful comments on the contents of the HL White collection. Nick Kolichis encouraged me to think about alternative hypotheses, and provided an expert assessment of the origin of the Jarnadup clutch. Ian Abbott, John Blyth, Michael Craig and Ron Johnstone provided useful comments on earlier versions of this manuscript. Financial support for the work was provided by the Department of Conservation and Land Management, supplemented by private funds of A.H. Burbidge, J.A. Raines and N. Kolichis.

\section{REFERENCES}

Abbott, I. (1998). Avifauna of the Irwin Inlet - Broke Inlet - Mt Frankland region of south-west Western Australia, 1912-1913. CALMScience 2: 373-386.

Baird, R.F. (1991). Holocene avian assemblage from Skull Cave (AU-8), south-western Australia. Records of the Western Australian Museum 15: 267-286.

Burbidge, A. H. (2003). Birds and fire in the Mediterranean climate of south-west Western Australia. In 'Fire in Ecosystems of south-west Western Australia: Impacts and Management.' (Eds I. Abbott and N. Burrows) pp. 321-347. (Backhuys: Leiden.)

Burbidge, A.A. (2004). Threatened Animals of Western Australia. Department of Conservation and Land Management, Perth.

Cale, P. and Burbidge, A.H. (1993). Research Plan for the Western Ground Parrot, Western Bristlebird and Western Whipbird. Unpublished report to Australian National Parks and Wildlife Service. (51 pp).

Condon, H.T. (1951). Notes on the birds of South Australia: occurrence, distribution and taxonomy. South Australian Ornithologist 20: 26-68.

Fisher, C.T. (1992). The Importance of early Victorian Natural Historians in the Discovery and Interpretation of the Australian Fauna, with special reference to John Gilbert. Ph.D. thesis, Liverpool Polytechnic.

Garnett, S. and Crowley, G. (2000). The Action Plan for Australian Birds 2000. Environment Australia, Canberra.

Higgins, P.J. and Peter, J.M. (2002). Handbook of Australian, New Zealand and Antarctic Birds. Volume 6 Pardalotes to shrike-thrushes. Oxford University Press, Melbourne. 
Johnstone, R.E. and Storr, G.M. (2004). Handbook of Western Australian Birds. Volume II. Passerines (Blue-winged Pitta to Goldfinch). Western Australian Museum, Perth.

Keast, A. (1957). Variation in the bristle-birds (Dasyornis). Proceedings of the Royal Zoological Society of New South Wales 1955-56: 43-46.

Male, B. (1995). Recovery actions for threatened species an Australian perspective. Ibis 137: S204-S208.

McEvey, A. R. (1981). Appendix 3. Notes on the H.L. White collections. In 'The White Family of Belltrees'. (Ed. J. White) pp. 182-190. Seven Press: Sydney.

North, A.J. (1901). Nests and Eggs of Birds found breeding in Australia and Tasmania. Vol. 1. Australian Museum, Sydney.

Robin, L. (2001). 'The Flight of the Emu. A Hundred Years of Australian Ornithology.' (Melbourne University Press: Melbourne.)
Schodde, R. and Mason, I.J. (1999). The Directory of - Australian Birds. Passerines. CSIRO Publishing, Collingwood, Victoria.

Smith, G.T. (1987). Observations on the biology of the Western Bristlebird Dasyornis longirostris. Emu 87, 111-118.

Taylor, M. (1985). The search for the Western Bristlebird. Landscope 1(1): 29-30.

Whittell, H.M. (1936). The bristle-birds of Western Australia. Emu 35, 196-201.

Whittell, H.M. (1941). A review of the work of John Gilbert in Western Australia. Emu 41: 112-129.

Manuscript accepted 27 March 2007 